\title{
Humic acid and enzymes in canola-based broiler diets: Effects on bone development, intestinal histomorphology and immune development
}

\author{
A.R.P. Disetlhe ${ }^{1,2}$, U. Marume ${ }^{1,2 \#}$, V. Mlambo, ${ }^{1,2} \&$ I. Dinev ${ }^{3}$ \\ ${ }^{1}$ Department of Animal Sciences, School of Agriculture Science, Faculty of Agriculture, Science and Technology, North \\ West University, P Bag X 2046, Mmabatho, South Africa \\ ${ }^{2}$ Food Security and Safety Niche area, Faculty of Agriculture, Science and Technology, North West University, P Bag X \\ 2046, Mmabatho, 2735, South Africa \\ ${ }^{3}$ Department of General and Clinical Animal Pathology, Faculty of Veterinary Medicine, Trakia University,6000 Stara \\ Zagora, Bulgaria
}

(Received 28 August 2017; Accepted 25 September 2017; First published online 17 October 2017)

\begin{abstract}
Copyright resides with the authors in terms of the Creative Commons Attribution 4.0 South African Licence.
See: http://creativecommons.org/licenses/by/4.0/za

Condition of use: The user may copy, distribute, transmit and adapt the work, but must recognise the authors and the South African Journal of Animal Science.
\end{abstract}

\begin{abstract}
The objective of the study was to investigate the effects of dietary inclusion of humic acid and enzymes on bone development, histomorphology of internal organs and the incidence of rickets in broiler chickens fed canola-based diets. In the study, Cobb 500 broiler chicks were used and the following five dietary treatments were administered: control (commercial diet); CM (17.5\% canola meal inclusion); CMEnz $(17.5 \% \mathrm{CM}$ inclusion + 0.3g/kg Axtra XAP); CMPh (17.5\% CM inclusion + 1.5\% potassium humate $(\mathrm{PH})$ ); and CMEnzPh (17.5\% CM inclusion $+1.5 \% \mathrm{PH}+0.3 \mathrm{~g} / \mathrm{kg}$ Axtra XAP). These diets were formulated and randomly allocated to 20 pens (experimental units), each housing 11 birds. The birds were phase fed, with the starter diet being given to all birds from day 1 to day 14. During the grower (days 15-28) and finisher phases (days 29-42) birds were fed the experimental diets. Diet differed significantly across all treatments on latency-to-lie (LTL) test. Broilers fed CMEnz had the lowest standing persistence (2.88 $\pm 2.69 \mathrm{~min})$ and those on CMEnzPh had the highest $(11.19 \pm 2.69 \mathrm{~min})$, followed by those offered the control diet $(9.05 \pm$ $2.69 \mathrm{~min}$ ). Gross lesion analysis displayed high prevalence of rickets in boilers fed CMEnz diet compared with all other dietary treatments. Intestinal morphometric parameters demonstrated some dietary differences in the height and width of the intestinal villi and intestinal crypts. In conclusion, inclusion of humic acid in canola-based diets appeared to positively influence digestion and assimilation dynamics that were consequential to the improvement in bone and immune development in broilers.
\end{abstract}

Keywords: Bursae of Fabricius, latency-to-lie, poultry, thymus, tibia biomechanics, tibia gross lesions

\#Corresponding author: upenyu.marume@nwu.ac.za

\section{Introduction}

In broiler chickens selection for rapid growth over a short production cycle has inadvertently resulted in high incidences of immune deficiency and bone disorders such as tibia dyschondroplasia, rickets and associated valgus-varus deformities leading to lameness (Flemming, 2008; Dinev, 2012). Bone conditions related to weakness of legs have been identified as severe problems in broiler chickens, which grow really fast, causing low economic profits because of lower productive efficiency, which is brought about by mortality and culling, and raising concerns about the welfare of the chickens (Dinev -Feria et al., 2014).

The rapid growth over a short production cycle has been achieved through use of high-quality nutrient sources and commercial growth promotants. Nevertheless, high value nutrient sources, such as soybean meal, are becoming expensive and inaccessible to many poultry producers. Potential alternatives, such as canola meal (CM), have been explored although their use has been limited by the high fibre content and low feeding value compared with soybean meal (SBM) (Wickramasuriya et al., 2015; Ivarsson \& Wall, 2017). Nevertheless, the inclusion of enzymes and organic acids, such as humic acids, has been observed to improve the digestibility of poor protein sources such as CM, promoting the effective release of nutrients and other elements that influences the general health of chickens (Luckstadt \& Mellor, 2011; Khan \& lqbal, 2015).

The inclusion of exogenous enzymes in poor nutrient sources may ensure effective release and assimilation of nutrients and minerals in the gut, stimulating efficient nutrient utilization and, more 
importantly, promoting active bone growth (Ozturk et al., 2010; Kim et al., 2017). On the other hand, organic acids, including humic acids, have variable physical and chemical properties that allow them to influence gastronomic functions of feed in poultry. Humic acid has the potential to induce intestinal morphological alterations, stimulate changes in intracellular divalent calcium levels, and act as dilators, increasing mucosal and cellular permeability (Pizzari et al., 2000; Johnsson et al., 2015). Increased permeability allows easier assimilation of minerals from the gut and their transfer from blood to the bone and cells, resulting in effective bone development (Stepchenko et al., 1991; Dinev, 2012). Like other organic acids, humic acid may play a significant role in the development of immune organs, particularly the bursa of Fabricius and thymus, which are the major components of the avian immune system (Abdel-Fattah et al., 2008; Ghazala et al., 2011).

Studies have been conducted on the effects of enzymes and humic acid salts on nutrient utilization and growth performance in poultry and some animal species. However, information on the influence of enzymes and humic acid salts inclusion in canola-based diets on organ and bone development in broilers is scarce. This study was therefore conducted to determine the influence of potassium humate and exogenous enzyme inclusion on intestinal histomorphology, bone and immune development, and incidents of rickets in broiler chickens fed canola-based diets.

\section{Materials and methods}

The study was conducted at North-West University Experimental Farm. A total of 220 day-old chicks (Cobb 500) were randomly allocated to 20 pens (each pen measuring $3.5 \times 1.0 \times 1.85 \mathrm{~m}$ and housing 11 birds) designed to meet the animal welfare standards for optimum production of broilers. Five dietary treatments were formulated and randomly allocated to the 20 pens (experimental units) in a completely randomized experimental design. During the first three days of brooding, the ambient temperature in the broiler house was kept between 32.5 and $33^{\circ} \mathrm{C}$, but was gradually reduced, reaching $26{ }^{\circ} \mathrm{C}$ at 14 days of age. Stress packs were given to the chicks for three days. The birds were phase-fed, starting with the provision of starter ration to all the birds from days 1 to 14 . Experimental diets were offered only during the grower ( $d$ 15-28) and finisher ( $d$ 29-42) phases. Water was provided ad libitum. The experimental procedures were approved by MAREC Animal Research Ethics Committee of North-West University (Ethics number NWU-00516-16-S9). No mortalities were recorded over the period of study.

The five experimental diets were formulated according to the commercial feed formulation standards to meet the nutrient requirements for the grower and finisher phases (NRC, 1994). The control diet was a commercial diet whose major protein source was $100 \%$ soybean (SBM), while the other four diets contained canola meal $(\mathrm{CM})$ at $17.5 \%$ inclusion. Five dietary treatments were formulated as follows: i) Control (commercial broiler diet); ii) CM (17.5\% canola meal inclusion); iii) CMEnz (CM + 0.3 g/kg Axtra XAP); iv) CMPh $(\mathrm{CM}+1.5 \%$ potassium humate $(\mathrm{PH}))$; and v) CMEnzPh $(\mathrm{CM}+1.5 \% \mathrm{PH}+0.3 \mathrm{~g} / \mathrm{kg}$ Axtra XAP). The $17.5 \%$ canola inclusion was the maximum rate possible for formulation of a balanced broiler diet, while the inclusion level of enzymes was the recommended level provided by feed companies for ingredients such as canola, which are poor protein sources that contain high fibre. The inclusion level of potassium humate was derived based on the ranges from the literature (Ozturk et al., 2012; Ragaa \& Korany, 2016). Ingredients and dietary formulae are shown in Table 1, and Table 2 shows the nutritional compositions of the diets. Nearinfrared reflectance spectroscopy was used to determine the proximate composition of the diets.

In terms of the standing persistence of broilers at day 35, four chickens per replicate were exposed to the LTL test, which measures standing persistence, as described by Berg \& Sanotra (2003). This test is established on the concept that body interaction with water is a novel experience for broiler chickens. In brief each bird was placed in a plastic container containing $3 \mathrm{~cm}$ water at $32{ }^{\circ} \mathrm{C}$. The time until each bird sat down was recorded, according to the principle that the better leg health the broiler had, the longer it would stand up to avoid body contact with the water. If the chicken was still standing after 600 seconds, which is equivalent to 10 minutes, the test was interrupted, and the legs were judged to be strong and healthy.

Tibia gross lesion analysis was conducted to assess the prevalence of rickets in broilers from various dietary treatments. At necropsy on day 42, five tibiae per treatment were obtained for gross lesion assessment. The muscles around the tibia were carefully removed, then the proximal end was dissected with very sharp scalpel to expose the epiphyseal plate. The growth plates of the tibia bones were examined visually for gross lesions.

In terms of tibia linear parameters and bone breaking strength at necropsy on day 42 , six right tibiae from each replicate were surgically removed, de-fleshed and cleaned of all tissue, including cartilage caps (periosteum) by hand, and weighed to obtain the tibia weight, tibia diameter proximal end, tibia width diameter tibia length diameter and tibia diameter distal end were determined using a Toshiba-Rotanode $\mathrm{x}$ ray (Toshiba Electron Tubes and Devices, Tochigi, Japan) connected to the point-of-care (CR140) system for digital imaging. After linear measurement, each of the tibiae was placed on an adjustable three-point bend/snap fixture fitted on a heavy-duty TA-XT platform of a texture analyser (model TA-XT plus, Stable 
Table 1 Ingredient composition of standard broiler diet and diets containing canola, enzymes and humic acid in grower and finisher phases.

\begin{tabular}{|c|c|c|c|c|c|c|c|c|c|c|}
\hline \multirow{3}{*}{ Ingredients } & \multicolumn{10}{|c|}{ Dietary treatments ${ }^{1}$} \\
\hline & \multicolumn{5}{|c|}{ Grower } & \multicolumn{5}{|c|}{ Finisher } \\
\hline & Control & $\mathrm{CM}$ & CMEnz & CMPh & CMEnzPh & Control & $\mathrm{CM}$ & CMEnz & CMPh & CMEnzPh \\
\hline $\begin{array}{l}\text { Yellow maize- } \\
\text { fine }\end{array}$ & 69.9 & 59.5 & 59.5 & 59.5 & 59.5 & 76.2 & 66.4 & 66.4 & 66.4 & 66.4 \\
\hline Canola oilcake & 0 & 17.5 & 17.5 & 17.5 & 17.5 & 0 & 17.5 & 17.5 & 17.5 & 17.5 \\
\hline Prime gluten 60 & 1.8 & 2.4 & 2.4 & 2.4 & 2.4 & 1.27 & 1.8 & 1.8 & 1.8 & 1.8 \\
\hline Full fat soya & 5.1 & 5.1 & 5.1 & 5.1 & 5.1 & 1.53 & 1.61 & 1.6 & 1.59 & 1.54 \\
\hline Soybean meal & 19.7 & 2.22 & 2.21 & 2.22 & 2.22 & 18 & 0.5 & 0.6 & 0.5 & 0.5 \\
\hline Limestone & 1.45 & 1.22 & 1.22 & 1.22 & 1.22 & 1.30 & 1.07 & 1.07 & 1.07 & 1.07 \\
\hline MCP & 0.72 & 0.56 & 0.56 & 0.56 & 0.56 & 0.50 & 0.33 & 0.33 & 0.33 & 0.33 \\
\hline Salt-fine & 0.32 & 0.32 & 0.32 & 0.32 & 0.32 & 0.33 & 0.33 & 0.33 & 0.33 & 0.33 \\
\hline $\mathrm{NaHCO}_{3}$ & 0.17 & 0.16 & 0.16 & 0.16 & 0.16 & 0.13 & 0.12 & 0.12 & 0.12 & 0.12 \\
\hline Choline powder & 0.08 & 0.08 & 0.08 & 0.08 & 0.08 & 0.08 & 0.08 & 0.08 & 0.08 & 0.08 \\
\hline Lysine & 0.28 & 0.29 & 0.29 & 0.29 & 0.29 & 0.26 & 0.27 & 0.27 & 0.27 & 0.27 \\
\hline L-Threonine & 0.04 & 0 & 0 & 0 & 0 & 0.03 & 0 & 0 & 0 & 0 \\
\hline Methionine & 0.19 & 0.18 & 0.18 & 0.18 & 0.18 & 0.16 & 0.09 & 0.09 & 0.09 & 0.09 \\
\hline $\begin{array}{l}\text { PX P2 Br Gr } \\
\text { with phytase }\end{array}$ & 0.17 & 0.17 & 0.17 & 0.17 & 0.17 & 0 & 0 & 0 & 0 & 0 \\
\hline $\begin{array}{l}\text { PX P3 Br Fin } \\
\text { with phytase }\end{array}$ & 0 & 0 & 0 & 0 & 0 & 0.17 & 0.17 & 0.17 & 0.17 & 0.17 \\
\hline Coxistac & 0.05 & 0.05 & 0.05 & 0.05 & 0.05 & 0.05 & 0.05 & 0.05 & 0.05 & 0.05 \\
\hline Olaquindox & 0.04 & 0.04 & 0.04 & 0.04 & 0.04 & 0.04 & 0.04 & 0.04 & 0.04 & 0.04 \\
\hline $\begin{array}{l}\text { Axtra XAP } \\
(\mathrm{g} / \mathrm{kg})\end{array}$ & 0 & 0 & 0.3 & 0 & 0.3 & 0 & 0 & 0.3 & 0 & 0.3 \\
\hline $\begin{array}{l}\text { Potassium } \\
\text { humate (\%) }\end{array}$ & 0 & 0 & 0 & 1.5 & 1.5 & 0 & 0 & 0 & 1.5 & 1.5 \\
\hline
\end{tabular}

${ }^{1}$ Dietary treatments: control: commercial broiler diet; CM: commercial broiler diet in which $17.5 \%$ of SBM was replaced by canola meal; CMEnz: CM diet + $0.3 \mathrm{~g} / \mathrm{kg}$ Axtra XAP enzyme complex; CMPh: CM diet $+1.5 \%$ potassium humate; and CMEnzPh: CM diet + 1.5\% PH + 0.3g/kg Axtra XAP enzyme complex; $\mathrm{NaHCO}_{3:}$ Sodium bicarbonate; MCP:

monocalcium phosphate.

Microsystmems, Surrey, UK) and broken with a 6-cm flat head probe attached to a 50-kg load cell reporting the breaking force in Newtons. The distance between the bone supports was $50 \mathrm{~mm}$. The breaking bone strength was recorded as the peak load before the bone breakage.

For the histomorphology of internal organs based on random sampling, six tissue samples per replicate were obtained for histological examination of the bursae of Fabricius, thymi and sections of the small intestines (duodenum, jejunum and ileum) and the caeca. These tissue samples were thoroughly washed with chilled phosphate buffer (PBS) (pH -7.2). Intestinal segments measuring $1 \mathrm{~cm}$ in length were then dissected and fixed on cork lamellae. They were washed again with PBS buffer to eliminate intestinal contents and placed in cold $10 \%$ buffered and neutralized formalin. Thereafter, the samples were embedded in paraffin and then micro samples with a thickness of approximately $4 \mu \mathrm{m}$ were obtained and stained with haematoxylin and eosin $(H / E)$. The various intestinal morphometric measurements were then determined using a light microscope (OPTIKA B-500, OPTIKA SRL, Ponteranica, Italy). The parameters included the height and width of the intestinal villus and width of the crypts. 
Table 2 Nutrient composition (\%) of standard and canola-containing grower and finisher diets for broilers

\begin{tabular}{|c|c|c|c|c|}
\hline \multirow{2}{*}{ Parameters } & \multicolumn{2}{|c|}{ Standard broiler diet composition } & \multicolumn{2}{|c|}{ Canola oil cake diet composition } \\
\hline & Grower & Finisher & Grower & Finisher \\
\hline Volume & 100 & 100 & 100 & 100 \\
\hline Moisture & 10.93543 & 11.27404 & 11.345062 & 11.579352 \\
\hline $\mathrm{ME}^{1}$ & 11.79982 & 11.91972 & 12.099266 & 12.29989 \\
\hline Protein & 18.93943 & 16.89748 & 18.800643 & 16.905623 \\
\hline Fat & 6.244323 & 6.389549 & 5.961664 & 5.998489 \\
\hline Fibre & 4.175833 & 4.027193 & 4.314995 & 4.205758 \\
\hline Ash & 4.845047 & 4.254113 & 4.815068 & 4.218272 \\
\hline Linoleic & 2.970173 & 2.527973 & 2.963169 & 2.550331 \\
\hline Choline & 1285.453 & 1159.593 & 1283.75833 & 1173.79636 \\
\hline Calcium & 0.850021 & 0.750026 & 0.850056 & 0.750005 \\
\hline Phosphorus & 0.562513 & 0.501338 & 0.596865 & 0.495018 \\
\hline Sodium & 0.180022 & 0.169984 & 0.179983 & 0.170003 \\
\hline Chlorine & 0.3 & 0.299997 & 0.299991 & 0.3 \\
\hline Potassium & 0.732957 & 0.655133 & 0.76275 & 0.684109 \\
\hline Arginine & 1.10153 & 0.959095 & 1.100416 & 0.957639 \\
\hline
\end{tabular}

${ }^{1} \mathrm{ME}:$ metabolizable energy

Data on LTL test, intestinal morphometric measures and tibia parameters were analysed using GLM procedure of SAS (2010). The statistical model was as follows:

$Y_{i j k}=\mu+D_{i}+\varepsilon_{i j k}$

Where: $Y_{i j k}=$ response variables

$\mu=$ population mean

$D_{i}=$ effect diets

$\varepsilon_{i j k}=$ random error assumed to be normally and independently distributed

For all statistical tests, statistical significance was declared at $P<0.05$.

\section{Results}

Diet differed $(P<0.05)$ across all treatments on latency-to-lie test (Table 3$)$. In comparison with those fed the control diet, broilers fed CMEnz and CM diets had lower standing persistence. The highest standing persistency was observed in the birds fed CMEnzPh diet $(11.19 \pm 2.69 \mathrm{~min})$. The effects of potassium humate and enzyme complex inclusion in canola meal diets on tibia bone parameters are also presented (Table 3 ). Diet had no effect on tibia biomechanical parameters. High amounts $(P<0.05)$ of calcium $(\mathrm{Ca})$ and phosphorus (P) were observed in the control and CMPh treatment groups (Table 4). However, the two treatments had the lowest Ca:P ratios. CMPh diet was observed to be a good source of potassium and magnesium as it had the highest values for the two elements.

Results on the gross lesion analysis and incidence of rickets showed that broiler chickens in the control treatment had a mix of long and short tibiae, where longer tibia bones indicated the normal bones, while the short tibia bone indicated the presence of rickets in bones. Moreover, the white stroma of the tibia bone from broilers in the control was enlarged compared with the normal bone. The proximal metaphyseal region of the bones also varied with differences of between $2 \mathrm{~mm}$ and $3 \mathrm{~mm}$. Furthermore, the difference in the redness of the tibia bone marrow was not distinguishable, showing a lack of clear transition between the hypertrophic and proliferative zones. 
Table 3 Effects of humic acid and enzyme complex inclusions on tibia biomechanics of broilers fed canolabased diets

\begin{tabular}{|c|c|c|c|c|c|c|}
\hline \multirow{2}{*}{ Parameters } & \multicolumn{5}{|c|}{ Dietary treatments ${ }^{1}$} & \multirow{2}{*}{ SEN } \\
\hline & Control & $\mathbf{C M}$ & CMEnz & CMPh & CMEnzPh & \\
\hline Latency-to-lie test (min) & $9.05^{\mathrm{ab}}$ & $6.49^{b}$ & $2.88^{\mathrm{c}}$ & $8.63^{b}$ & $11.19^{a}$ & 2.69 \\
\hline Tibia weight (g) & 11.38 & 13.45 & 12.67 & 12.15 & 14.13 & 0.89 \\
\hline Tibia diameter proximal end (cm) & 2.29 & 2.19 & 2.32 & 2.25 & 2.37 & 0.10 \\
\hline Tibia width diameter (cm) & 0.77 & 0.93 & 0.78 & 0.79 & 0.80 & 0.40 \\
\hline Tibia length diameter (cm) & 9.77 & 10.19 & 9.75 & 9.98 & 10.12 & 0.15 \\
\hline Tibia diameter distal end (cm) & 1.79 & 1.95 & 1.73 & 1.69 & 1.81 & 0.08 \\
\hline Bone breaking strength $(\mathrm{kg})$ & 33.96 & 28.68 & 31.99 & 35.19 & 36.57 & 2.13 \\
\hline
\end{tabular}

a, b, c, Means in the same row with different superscripts are significantly different $(P<0.05)$.

${ }^{1}$ Dietary treatments: control (commercial broiler diet), CM (17.5\% canola meal inclusion), CMEnz (17.5\% CM inclusion $+0.3 \mathrm{~g} / \mathrm{kg}$ Axtra XAP), CMPh (17.5\% CM inclusion + 1.5\% potassium humate $(\mathrm{PH}))$, and $\mathrm{CMEnzPh}$ $(17.5 \% \mathrm{CM}$ inclusion $+1.5 \% \mathrm{PH}+0.3 \mathrm{~g} / \mathrm{kg}$ Axtra XAP)

Table 4 Tibia ash and macro mineral content of broiler tibia bone fed dietary treatments

\begin{tabular}{|c|c|c|c|c|c|c|}
\hline \multirow{2}{*}{ Parameters } & \multicolumn{5}{|c|}{ Dietary treatments ${ }^{1}$} & \multirow{2}{*}{ SEM } \\
\hline & Control & CM & CMEnz & CMPh & CMEnzPh & \\
\hline Tibia ash (\%) & 41.73 & 37.58 & 38.54 & 35.44 & 39.38 & 3.99 \\
\hline Calcium (mg/l) & $14960.44^{b}$ & $11765.35^{\mathrm{c}}$ & $11895.04^{c}$ & $15064.08^{b}$ & $6579.65^{\mathrm{a}}$ & 1385.66 \\
\hline Phosphorus (mg/l) & $7749.46^{c}$ & $5466.20^{\mathrm{ac}}$ & $5621.34^{c}$ & $7360.42^{b}$ & $3277.70^{\mathrm{a}}$ & 174.73 \\
\hline Magnesium (mg/l) & $141.54^{b c}$ & $116.11^{\mathrm{c}}$ & $116.11^{c}$ & $151.52^{b}$ & $64.35^{\mathrm{a}}$ & 13.55 \\
\hline Sodium (mg/l) & 195.68 & 170.53 & 216.19 & 208.29 & 117.18 & 27.19 \\
\hline Potassium (mg/l) & $438.41^{b c}$ & $450.60^{b c}$ & $244.23^{a}$ & $570.97^{b}$ & $511.64^{b}$ & 58.31 \\
\hline Ca: P & $1.93^{\mathrm{a}}$ & $2.15^{b}$ & $2.12^{b}$ & $2.04^{a}$ & $2.01^{a}$ & 0.211 \\
\hline
\end{tabular}

${ }^{a . b, c}$ Means in the same row with different superscripts are significantly different $(P<0.05)$

$\mathrm{Ca}: \mathrm{P}$ : calcium phosphorus ratio

${ }^{1}$ Dietary treatments: control (commercial broiler diet), CM (17.5\% canola meal inclusion), CMEnz (17.5\% CM inclusion + $0.3 \mathrm{~g} / \mathrm{kg}$ Axtra XAP), CMPh (17.5\% CM inclusion + 1.5\% potassium humate $(\mathrm{PH}))$, and $\mathrm{CMEnzPh}$ $(17.5 \% \mathrm{CM}$ inclusion + 1.5\% PH + $0.3 \mathrm{~g} / \mathrm{kg}$ Axtra XAP)

The tibia bones of broilers fed CM showed abnormal conversion of organic material in the bone mass, with the white stroma revealing a transition of the proliferative zone of the growth plate into a curve-shaped projection. This observation could be because of disproportionate amounts of calcium and phosphorus in the diet. The tibiae from broilers in CMEnz, CMPh and CMEnzPh diets showed gross lesions associated with rickets, manifested by the enlargement of the proximal metaphysis. The proliferative region also showed a curved deformation and the transition between the hypertrophic and proliferative zones was irregular. This was a clear sign of leg weakness, which could cause fracture of the bones. Broilers in CMEnz showed more signs of bone abnormalities compared with all other treatments.

Microscopic analysis of the intestinal tract of the broilers showed desquamated processes in mild to moderate degrees, affecting the apical part of the intestinal villi, which were prevalent in broilers from the control and CMEnzPh groups. However, in all dietary treatments traces to mild manifestations of mucosal hyperaemia and sub-mucous oedema were observed. The results on intestinal morphometric parameters demonstrated some differences in the height and width of the intestinal villi and in the width of the intestinal crypts (Table 5). The values of these three parameters showed some significant variations $(P<0.05)$ across 
the five dietary treatments. The widest and tallest intestinal villi were observed in broilers offered CMEnz and CMPh diets, and the deepest crypts were observed in broilers offered the same diets (Table 5). Examination of organs of the central immune system (thymus and bursae of Fabricius) revealed some variation in the density of lymphoid tissue build-up in their structural elements. In CM and CMEnz chickens, well-established uniformly distributed and well-defined density of lymphoid tissue in the peripheral and central follicles building parenchyma organs was observed. Nevertheless, chickens in the control had some reduction in thymic volume units and the follicles of the bursa of Fabricius, in the cortical and in the core regions. The central follicles in these cases were characterized by poorly pronounced density of lymphoid tissue (light area).

Table 5 Effects of enzymes and humic acid inclusions on intestinal morphometric measurements in broilers fed canola-based diets $($ Bar $=100 \mu \mathrm{m})$ gtg

\begin{tabular}{lcccccc}
\hline \multirow{2}{*}{ Morphometric $(\boldsymbol{\mu m})$} & \multicolumn{5}{c}{ Dietary treatments $^{1}$} & \multirow{2}{*}{ SEM } \\
\cline { 2 - 5 } & Control & CM & CMEnz & CMPh & CMEnzPh & \\
\hline Villus height & $511.05^{\mathrm{ab}}$ & $308.46^{\mathrm{a}}$ & $565^{\mathrm{b}}$ & $687.29^{\mathrm{b}}$ & $300.47^{\mathrm{a}}$ & 51.31 \\
Villus width & $148.35^{\mathrm{b}}$ & $150.23^{\mathrm{b}}$ & $148.27^{\mathrm{b}}$ & $176.98^{\mathrm{C}}$ & $106.88^{\mathrm{a}}$ & 26.32 \\
Crypt depth & 23.55 & 23.01 & 46.03 & 46 & 39.48 & 3.25 \\
Villus:crypt ratio & 21.7 & 13.40 & 12.27 & 14.94 & 7.61 & 1.64
\end{tabular}

${ }^{a . b, c}$ Means in the same row with different superscripts are significantly different $(P<0.05)$

${ }^{1}$ Dietary treatments: Control (commercial broiler diet), CM (17.5\% canola meal inclusion), CMEnz (17.5\% CM inclusion + $0.3 \mathrm{~g} / \mathrm{kg}$ Axtra XAP), CMPh (17.5\% CM inclusion $+1.5 \% \mathrm{PH})$,

and CMEnzPh (17.5\% CM inclusion + 1.5\% PH + 0.3g/kg Axtra XAP)

\section{Discussion}

The LTL test as described by Weeks et al. (2002) is a prominent method that was developed to measure standing persistence, which is an indirect measure of bone development and bone strength in broilers. Water as an aversive stimulus has been shown to provide avoidance motivation, resulting in broilers with strong bones being able to stand for 600 seconds, whereas those with poor bone development might succumb to their weight and sit down sooner (Berg \& Sanotra, 2003; Yang et al., 2016). In the current study, broilers that had humic acid in their diets had the highest standing persistency, while those fed a diet with enzyme complex only had the weakest bones. The longer standing persistency in broilers fed diets with humic acid could be a result of the high amounts of minerals in canola diets, coupled with the actions of humic acid in stimulating mineral assimilation dynamics in the gut and transfer of blood to the bone and cells, allowing for development of stronger bones (Stepchenko et al., 1991; Ghosh et al., 2016).

Generally, gross lesion analysis of the tibiae revealed clear evidence of subclinical rickets in broilers from all treatments, although CMEnz was affected more. This was attributed to the disproportionate amount of $\mathrm{Ca}$ and $\mathrm{P}$ in the diets. However, it could not be established in the current study whether the rickets were hypocalcaemic or hypophosphataemic. As observed in other studies, the type of rickets could not be determined owing to insufficient intensity of lesion occurrence in the bones (Dinev, 2009; 2011). Rickets are normally manifested as a result of dietary calcium $(\mathrm{Ca})$, phosphorus $(\mathrm{P})$, and vitamin D3 deficiency, impaired $\mathrm{Ca} / \mathrm{P}$ ratio and impaired absorption of one or both of these macro-elements (Dinev, 2011). Erroneous feed mixing has also been shown to provoke outbreaks (Riddell, 1992). In both forms, namely hypocalcaemic or hypophosphataemic, the proper calcification of cartilage is impaired. In the current study, it appeared that the lesions were not severe to the level of causing lameness in all treatments, including CMEnz, which had the highest incidence of subclinical rickets.

The observed transition of the proliferative zone of the growth plate into wedge-shaped projections in most of the tibiae was consistent with observations on broilers affected by rickets, as reported in other studies (Dinev, 2012). The age at which lesions are usually prevalent in chickens is around 35 days. This period is associated with intensive muscle growth. Hence, cumulative weight may also be used to predict lesions (Dinev, 2012). Moreover, mineralization during this period may affect bone strength in that it allows the skeleton to resist gravity and additional loading (Boivin \& Meunier, 2002).

Although no differences were observed with regard to tibia bone parameters, a marginal increase in these measures was observed with the inclusion of canola meal and humic acid in the diets. Tibia 
biomechanical characteristics — such as bone breaking strength, bone density, bone mineral content and bone ash (Kwiecień, et al., 2016; Kim et al., 2017) are usually used as indicators of mineral adequacy in broiler diets. In the current study, the marginal increase in the parameters could be owing to the increased availability of $\mathrm{Ca}$ and $\mathrm{P}$ provided by canola in diets. Moreover, this could be attributed to the ability of humic acid to increase the degree of mineralization of the bone matrix (Stepchenko et al., 1991; Nkukwana et al., 2014). Generally, lack of specific mineral such as $\mathrm{Ca}$ and $\mathrm{P}$ in the diets can result in poor bone development (Selle et al., 2007; Kwiecień et al., 2016). The results of the current study suggest that bone breaking strength, bone density, bone mineral content and bone ash may be sensitive indicators of dietary $\mathrm{Ca}$ and $\mathrm{P}$ levels in broiler chickens (Hall et al., 2003; Venalainen et al., 2006). Furthermore, according to Talaty et al. (2009), insufficient dietary sources of $\mathrm{Ca}$ can result in blood hypocalcaemia, which may lead to reduced bone strength and mineralization. Calcium and phosphorus play an intrinsic role in the structure and metabolism of bone. Phosphorus also plays an intrinsic role in energy accumulation.

Good gut and intestinal health in broiler production is critical for optimization of feed utilization efficiency and ultimately growth rates. In the current study, the inclusion of canola meal and $\mathrm{PH}$ had minimal effects on gut mucosa, as highlighted by trace manifestation of mucosal hyperaemia and sub-mucosal edema, which was consistent with all dietary treatments. Nevertheless, the inclusion of canola and PH in diets significantly increased the intestinal morphometric parameters of the broilers. Generally, $\mathrm{PH}$ inclusion in diets has been observed to induce intestinal morphological modifications, increasing the mucosal and cellular permeability (Stepchenko et al., 1991).

The results of the study are consistent with findings from other studies, which demonstrated an increase in villus height and crypt depth with the inclusion of organic acids in broiler diets (Kum et al., 2010; Rodríguez-Lecompte et al., 2012). The trophic effect of the organic acids such as humic acid could be significant in stimulating the proliferation of normal crypt cells, enhancing healthy tissue turnover and maintenance (Leeson et al., 2005; Panda et al., 2009). Moreover, the presence of humic acid and secondary plant metabolites in canola may reduce bacterial colonization of the intestinal mucosa and facilitate increased efficiency of metabolic processes, as observed in other studies (Khan, 2013).

The bursa of Fabricius and thymus are central lymphoid tissues, peculiar to chickens, which are involved in immune response. Although some variation in the density of lymphoid tissue build-up in their structural elements was observed among the treatments, the inclusion of canola and humic acid in the diets appeared to improve the distribution and density of lymphoid tissue in the peripheral and central follicle building parenchyma organs in birds fed CM and CMEnzPh diets. This is significant because it indicates enhanced immune response in boiler chickens, as observed in other studies (Bahadori et al., 2017). Several studies have demonstrated the importance of organic acids such as humic acid in the immune response of birds. Abdel-Fattah et al. (2008), Ghazala et al. (2011), and Houshmand et al. (2012) observed that birds fed an organic acid-supplemented diet had heavier immune organs (bursa of Fabricius and the thymus) and a higher level of globulin in their serum, which is an indicator of immune response. Although broiler chickens in the control had some reduction in thymic volume units and the follicles of the bursa of Fabricius, this was not a manifestation of lymphocytic depletion of the thymus and bursa of Fabricius.

\section{Conclusion}

The results from the study showed that inclusion of humic acid in canola-based diets can positively influence bone and immune system development. Inclusion of enzyme alone resulted in broilers with the lowest standing persistence and a high prevalence of the bone abnormalities associated with rickets. Inclusion of humic acid and enzymes stimulated the growth of intestinal villi. Humic acid inclusion in diets was shown to improve distribution and density of lymphoid tissue in the peripheral and central follicle building tissues of the bursae of Fabricius and thymus, and thus had a positive influence on the immune development. Therefore, inclusion of humic acid in canola-based diets appeared to positively influence digestion and assimilation dynamics that were consequential to the improvement in bone and immune development in broilers. When all these results are evaluated generally, it is suggested that humic acid and enzymes that positively influence digestion and assimilation could be added to canola-based diets.

\section{Acknowledgements}

The authors thank the National Research Foundation (NRF) and the Health and Welfare Sector Education and Training Authority (HWSETA) for providing the research funds, and Nutrico (Pvt, Ltd) for providing potassium humate.

\section{Authors' Contributions}

ARPD contributed to the designing and conducting of the study, laboratory analysis, data analysis, and manuscript writing. UM was involved in the design of the study, statistics and interpretation of the data and manuscript writing, VM was involved in the constructive revision of the manuscript. ID participated in laboratory analysis, interpretation of the data and writing. 


\section{Conflict of Interest Declaration}

The authors declare that they have no competing interests.

\section{References}

Abdel-Fattah, S.A., El-Sanhoury, M.H., El-Mednay, N.M. \& Abdel-Azeem, F., 2008. Thyroid activity some blood constituents, organs morphology and performance of broiler chicks fed supplemental organic acids. Int. J. Poult. Sci, 7, 215-222.

Bahadori, Z., Esmaielzadeha, L., Karimi-Torshizib, M.A., Seidavic, A., Olivarese, J., Rojasd, S., Saleme, A.Z.M., Khusrof, A. \& Lópezg, S., 2017. The effect of earthworm (Eisenia foetida) meal with vermi-humus on growth performance, hematology, immunity, intestinal microbiota, carcass characteristics, and meat quality of broiler chickens. Livest. Sci, 202, 74-81.

Berg, C. \& Sanotra, G.S., 2003. Can a modified latency-to-lie test be used to validate gait-scoring results in commercial broiler flocks? Anim. Welfare, 12, 655-659.

Boivin, G. \& Meunier, P.J., 2002. The degree of mineralization of bone tissue measured by computerized quantitative contact microradiography. Calc. Tiss. Int. 70, 503-511.

Dinev, I., 2009. Clinical and morphological investigations on the prevalence of lameness, associated with femoral head necrosis in broiler chickens. Br. Poult. Sci, 3, 284-290.

Dinev, I., 2011. Rickets: Prevalence of its forms and association with other pathological conditions in broiler chickens. World's Poult. Sci. J. 68, 239-246.

Dinev, I., 2012. Clinical and morphological investigations on the incidence of forms of rickets and their association with other pathological states in broiler chickens. Res. Vet. Sci. 2, 273-277.

Flemming, R.M., 2008. Nutritional factors affecting poultry bone health. Pr. Nutri. Society 67, 177-183.

Ghazala, A.A., Atta, A.M., Elkloub, K., Mustafa, M.E.L., \& Shata, R.F.H., 2011. Effect of dietary supplementation of organic acids on performance, nutriens digestibility and health of broiler chicks. Int. J. Poult. Sci. 10,176-184.

Ghosh, A., Mandal, G.P., Roy, A. \& Patra, A.K., 2016 Effects of supplementation of manganese with or without phytase on growth performance, carcass traits, muscle and tibia composition, and immunity in broiler chickens. Livest. Sci.191, 80-85.

Hall, L.E., Shirley., R.B., Bakalli, R.I., Aggrey, S.E., Pesti, G.M. \& Edwards., H.M. Jr. 2003. Power of two methods for the estimation of bone ash of broilers. Poult. Sci. 82,414-418

Houshmand, M., Azhar, K., Zulkifli, I., Bejo, M.H. \& Kamyab, A. 2012. Effects of non-antibiotic feed additives on performance, immunity and intestinal morphology of broilers fed different levels of protein. S. Afr. J. Anim. Sci. 42, 22-32.

Ivarsson, E. \& Wall. H., 2017. Effects of toasting, inclusion levels and different enzyme supplementations of faba beans on growth performance of broiler chickens. J. Appl. Poult. Res. 0, 1-9.

Johnsson, M., Johnsson, K.B., Andersson, L., Jensen, P. \& Wright, D., 2015. Genetic regulation of bone metabolism in the chicken: similarities and differences to mammalian systems. PLOS Genetics 11, 5.

Khan, S.H., 2013. Probiotic microorganisms-identification, metabolic and physiological impact on poultry. World's Poult. Sci. J. 69, 601-612.

Khan, S.H. \& Iqbal, J., 2015. Recent advances in the role of organic acids in poultry nutrition. J. Appl. Anim. Res. 44, 359-369.

Kim, J.H., Han, G.P., Shin, J.E. \& Kil, D.Y., 2017. Effect of dietary calcium concentrations in phytase-containing diets on growth performance, bone mineralization, litter quality, and footpad dermatitis score in broiler chickens. Anim. Feed Sci. Technol. 229, 13-18.

Kum, S., Eren, U., Onol, A. \& Sandikci, M., 2010. Effects of dietary organic acid supplementation on the intestinal mucosa in broilers. Revue de Méd. Vét. 161, 463-468.

Kwiecień, M., Winiarska-Mieczan, A., Milczarek, A., Tomaszewska, E. \& Matras, J., 2016. Effects of zinc glycine chelate on growth performance, carcass characteristics, bone quality, and mineral content in bone of broiler chicken. Livest. Sci.191, 43-50.

Leeson, S., Namkung, H., Antongiovanni, M. \& Lee, E.H., 2005. Effect of butyric acid on the performance and carcass yield of broiler chickens. Poult. Sci. 84, 1418-1422.

Luckstadt, C. \& Mellor, S., 2011. The use of organic acids in animal nutrition, with special focus on dietary potassium deformate under European and Austral-Asian conditions. Recent Advanced Anim. Nutri. 18,123-130.

Mcdevitt, R.M., Mcentee, G.M. \& Rance, K.A., 2006. Bone breaking strength and apparent metabolisability of calcium and phosphorus in selected and unselected broiler chicken genotypes. Br. Poult. Sci. 47, 613-621.

NRC., 1994. Nutrient requirements of poultry. 9th ed., National Academy Press, Washington DC, USA.

Nkukwana,T.T., Muchenje, V., Masika, P.J., Hoffman, L.C. \& Dzama, K., 2014. The effect of Moringa oleifera leaf meal supplementation on tibia strength, morphology and inorganic content of broiler chickens. S. Afr. J. Anim. Sci. 44, 3.

Ozturk, E., Ocak, N., Coskun, I., Turhan, S. \& Erener, G., 2010. Effects of humic substance supplementation provided through drinking water on performance, carcass traits and meat quality of broilers. J. Anim. Physiol. Anim. Nutri. 94, 78-85

Ozturk, E., Ocak, N., Turan, A., Erener, G., Altop, A. \& Cankaya. S., 2012. Performance, carcass, gastrointestinal tract and meat quality traits, and selected blood parameters of broilers fed diets supplemented with humic substances. J. Sci. Food Agricult.92, 59-65. 
Panda, A.K., Rama Rao, S.V, Raju, M.V.L.N. \& Shyam, G.S., 2009. Effect of butyric acid on performance, gastrointestinal tract health and carcass characteristics in broiler chickens. Asian-Austral. J. Anim. Sci. 22, 10261031.

Pizzari, T. \& Birkhead, T.R., 2000. Female feral fowl eject sperm of subordinate males. Nature 405, 787-789.

Ragaa, N.M. \& Korany. R.M.S., 2016. Studying the effect of formic acid and potassium diformate on performance, immunity and gut health of broiler chickens. Anim. Nutrit. 2, 296-302.

Riddell, C., 1992. Noninfectious skeleton disorders of poultry - An overview. In: Bone biology and skeletal disorders in poultry. Poult. Sci. Symp.23, 119-145.

Rodríguez-Lecompte, J.C, Yitbarek, A, Brady, J., Sharif, S., Cavanagh, M.D, Crow, G., Guenter, W., House, J.D. \& Camelo-Jaimes, G., 2012. The effect of microbial nutrient interaction on the immune system of young chicks after early probiotic and organic acid administration. J. Anim. Sci. 90, 2246-2254.

Ruiz-Feria, C.A., Arroyo-Villegas, J.J., Pro-Martinez, A., Bautista-Ortega, J., Cortes-Cuevas, A., Narciso-Gaytan, C., Hernandez-Cazares, A. \& Gallegos-Sanchez, J., 2014. Effects of distance and barriers between resources on bone and tendon strength and productive performance of broiler chickens. Poult. Sci. 93, 1608-1617.

SAS., 2010. Statistical Analysis System Institute Inc. Users Guide, Carry, NC, USA.

Selle, P.H. \& Ravindran, V., 2007. Microbial phytase in poultry nutrition. Anim. Feed Sci. Technol. 135, 1-41.

Stepchenko, L.M., Zhorina, L.V. \& Kravtsova, L.V., 1991. The effect of sodium humate on metabolism and resistance in highly productive poultry (in Russain). Nauchnye Doklady Vysshei Shkoly. Biologicheskie Nauki, 10, 90-95.

Talaty, P.N., Katanbaf, M.N. \& Hester, P.Y., 2009. Life cycle changes in bone mineralization and bone size traits of commercial broilers. Poult. Sci. 88, 1070-1077.

Venäläinen, E., Valaja, J. \& Jalava, T., 2006. Effects of dietary metabolisable energy, calcium and phosphorus on bone mineralisation, leg weakness and performance of broiler chickens. Br. Poult. Sci. 47, 301-310.

Waldenstedt, L., 2006. Nutritional factors of importance for optimal leg health in broilers: A review Anim. Feed Sci. Technol. 126, 291-307.

Weeks, C.A., Knowles, T.G., Gordon, R.G., Kerr, A.E., Peyton, S.T. \& Tillbrook, N.T., 2002. New method for objectively assessing lameness in broiler chickens. Vet. Rec.151, 762-764.

Wickramasuriya, S.S., Yi, Y.J., Kim, J.C., Yoo, J., Kang, N.K. \& Heo. J.M., 2015. A review of canola meal as an alternative feed ingredient for ducks. J. Anim. Sci. Technol. 57, 29.

Williams, B., Solomon, S., Waddington, D., Thorp, B. \& Farquharson, C., 2000. Skeletal development in the meat-type chicken. Br. Poult. Sci.41, 141-149.

Williams, B., Waddington, D., Murray, D.H. \& Farquharson, C., 2004. Bone strength during growth: Influence of growth rate on cortical porosity and mineralization. Calc. Tiss. Int.74, 236-245.

Yan, F., Kersey, J.H., Fritts, C.A. \& Waldroup, P.W., 2006. Effect of phytase supplementation on the calcium requirement of broiler chicks. Int. J. Poult. Sci. 5, 112-120.

Yang, H., Wang, W., Wang, Z., Yang, Z., Wan, Y., Hou, B., Huang, K. \& Lu, H., 2016. Effects of early energy and protein restriction on growth performance, clinical blood parameters, carcass yield, and tibia parameters of broilers. J. Integrat. Agricult. 15, 1825-1832. 